\title{
CLIPLESS LAPAROSCOPIC CHOLECYSTECTOMY: THREE PORT ACCESS.
}

\footnotetext{
1. MBBS, MCPS, FCPS

Senior Registrar

Quaid e Azam Medical College

Bahawalpur.

2. MBBS

Medical Officer

Quaid e Azam Medical College

Bahawalpur.

3. MBBS, FCPS

Senior Registrar

Quaid e Azam Medical College Bahawalpur.

4. MBBS, FCPS

Senior Registrar

Quaid e Azam Medical College

Bahawalpur.
}

Correspondence Address:

Dr. Ghulam Hassan

Senior Registrar

Quaid e Azam Medical College

Bahawalpur.

hassansurgeon@gmail.com

Article received on:

15/04/2019

Accepted for publication:

10/10/2019

\section{INTRODUCTION}

Gallstone diseases, is a common problem nowadays, trend towards minimal invasive surgery played a pivotal role in treatment of symptomatic gallstones. Laparoscopic cholecystectomy is the gold standard procedure throughout the world for the treatment of symptomatic cholelithiasis. ${ }^{1,2}$ Many centers have special "short-stay" units or "23hour admissions" for postoperative observation following this procedure. ${ }^{1}$ Whereas it is true that no operation has been more profoundly affected by the advent of laparoscopy than cholecystectomy has, it is equally true that no procedure has been more instrumental in ushering in the laparoscopic age than laparoscopic cholecystectomy has. ${ }^{3}$

Four ports access (two $10 \mathrm{~mm}$ and two $5 \mathrm{~mm}$ ) and applying titanium clips on cystic duct and cystic artery remained the central methodology in laparoscopic cholecystectomy. ${ }^{4,5}$ Clips are foreign bodies and are expensive. Clip migration and stone formation are an infrequent but nevertheless documented complications. ${ }^{6}$ Single incision laparoscopic cholecystectomy even though showed much promise but failed to gain much popularity due to poor ergonomics. ${ }^{7}$

While patient protection remains same for both 3 port and 4 port approach to laparoscopic cholecystectomy ${ }^{8}$, lessening the number and size of ports improved post-operative pain and hospital stay. ${ }^{9}$ The advent of Harmonic scalpel has made a drift of surgeons choosing Harmonic over the traditional Maryland and Hook dissector as it saves time and is less injurious to surrounding tissue. ${ }^{10,11,12}$

We undertake this study to use this technology of Harmonic Scalpel to reduce the number of ports and decrease the $10 \mathrm{~mm}$ epigastric port to a $5 \mathrm{~mm}$ one for better post-operative recovery.

\section{MATERIAL \& METHODS}

Study conducted in surgical ward 2, Bahawal 
Victoria Hospital, from 2015 to 2017. 60 patients who are diagnosed as symptomatic gallstone disease were admitted in the hospital, routine investigations such as CBC, Serum Electrolytes, RFTS, LFTS were done. Pre op Anesthesia fitness were taken. During surgery first port was introduced by open method using umbilical stalk technique. Pneumoperitoneum created with $\mathrm{CO}_{2}$ and intraabdominal pressure maintained at $12 \mathrm{mmHg}$. Epigastric port of $5 \mathrm{~mm}$ introduced under vision. Third port of $5 \mathrm{~mm}$ introduced in Right Hypochondrium under vision. Gall bladder grasped and lifted. Cystic duct dissected and identified. Thread of Vicryl 2/0 passed through the window and brought out. An extracorporeal Roeder's knot created and tied on cystic duct. Cystic duct divided with harmonic ace distal to ligature. Cystic Artery dissected sealed and cut with harmonic ace. Gall bladder dissected, removed from liver bed and taken out from umbilical port. Post operatively Patients were evaluated for any clinical signs of bile leak or bleeding in the form of tachycardia, tachypnea, pain and abdominal distension. All patients were evaluated at bedside by ultrasound after 24 hours to assess any collection. All patients were discharged from the ward as early as possible. All patients were followed after 7 days for clinical assessment of bile leakage and ultrasonography for collection.

\section{RESULTS}

The mean demographic of the patients operated are depicted in Table-l. The patients' clinical parameters Pulse, Blood Pressure, Respiratory Rate, Temperature, unproportionate pain and abdominal distension were monitored postoperatively, Table-II summarizes the findings. All patients were vitally stable Table-III. Patients developed abdominal distension which lasted for 24 hours and resolved spontaneously. Ultrasound after 24 hours didn't show any collection in any patients. The mean length of hospital stay after surgery was 27 hours. Clinical Assessment and ultrasonography after 7 days didn't show any clinical sign of bile leakage or hemorrhage.

\section{Variable}

Number

Percentage

\begin{tabular}{|c|c|c|c|}
\hline \multicolumn{2}{|l|}{ Total patients } & 60 & \\
\hline \multicolumn{2}{|c|}{ Age in years: median (range) } & $47(27-69)$ & \\
\hline \multicolumn{2}{|l|}{ Sex: Male:Female } & $18: 42$ & $30: 70$ \\
\hline \multicolumn{4}{|c|}{ Table-I. Demographic Distribution of patients. } \\
\hline \multicolumn{2}{|l|}{ Variable } & \multicolumn{2}{|c|}{ Median (Range) } \\
\hline \multicolumn{2}{|l|}{ Pulse } & \multicolumn{2}{|c|}{$88 / \min (69-111)$} \\
\hline \multicolumn{2}{|c|}{ Blood Pressure (systolic) } & \multicolumn{2}{|c|}{$140 \mathrm{mmHg}(100-170)$} \\
\hline \multicolumn{2}{|l|}{ Respiratory Rate } & \multicolumn{2}{|c|}{$17 / \min (12-25)$} \\
\hline \multicolumn{2}{|l|}{ Temperature } & \multicolumn{2}{|c|}{$99 \mathrm{~F}(98-100)$} \\
\hline \multicolumn{2}{|l|}{ Unproportionate Pain } & \multicolumn{2}{|c|}{ None } \\
\hline \multicolumn{2}{|l|}{ Abdominal Distension } & \multicolumn{2}{|c|}{3 Patients } \\
\hline \multicolumn{4}{|c|}{ Table-II. Clinical Parameters. } \\
\hline Variable & \multicolumn{3}{|c|}{ No. of Patients with Collection } \\
\hline After 24 hours & \multicolumn{3}{|c|}{ None } \\
\hline After 7 days & \multicolumn{3}{|c|}{ None } \\
\hline
\end{tabular}

\section{DISCUSSION}

Laparoscopic Cholecystectomy (LC) has been the gold standard for acute and chronic cholelithiasis for decades now. ${ }^{1,2}$ Newer tweaks to improve the results has always been the goal of surgeons around the world. 4 port technique is widely used, with two $10 \mathrm{~mm}$ ports (umbilicus and Epigastrium) and two $5 \mathrm{~mm}$ ports, for laparoscopic cholecystectomy. ${ }^{4,5}$ Development of better equipment and increasing experience of surgeons has led to the standardization of 3 port LC with similar results for the procedure while producing better post-operative results in terms of pain management. ${ }^{13,14}$ Even in the 3-port technique a $10 \mathrm{~mm}$ port has to introduced in the epigastrium (other than the $10 \mathrm{~mm}$ umbilical port) for clip applicator. Incidence of pain is more marked at the epigastric site rather than the umbilicus. ${ }^{15}$ Use of Harmonic scalpel may render the need for this epigastric $10 \mathrm{~mm}$ port unnecessary.

Titanium clips has been the go-to method for sealing cystic duct and artery. Although rare but late complications of these clips have been reported. Complications like slippage of clip and, a more concerning, migration of clip into CBD with subsequent stone formation ${ }^{16}$ has been 
studied upon by some authors who concluded that these ultimately increase health $\operatorname{cost}^{17,18}$ and legal fees. ${ }^{19}$

The Ultrasound technology of Harmonic Scalpel is one of the latest inventions in laparoscopic surgery. While harmonic scalpel has successfully managed to control the cystic artery a more contemporary approach is to divide the cystic duct with Harmonic which showed promising results with minimal to no bile leakage eliminating the need of metal clips. ${ }^{11,20,21,22,23}$ While these results are hopeful but still there is considerable debate about the safety of sealing cystic duct with harmonic. Some authors have recommended that cystic duct should be safely ligated before using Harmonic to avoid bile spillage. ${ }^{24}$ While $2 / 0$ silk has been used by some authors to secure the cystic duct, ${ }^{25}$ we used 2/0 vicryl extracorporeal knot followed by sealing of distal cystic duct with Harmonic scalpel with encouraging results.

Using Harmonic scalpel and a single extracorporeal knot reduced the need of titanium clips and clip applicator altogether while at the same the $10 \mathrm{~mm}$ epigastric port can be reduced to $5 \mathrm{~mm}$. Improved training of surgeons leading to intracorporeal knots can further improve the procedure by decreasing operating time.

\section{CONCLUSION}

Using a harmonic scalpel to seal and divide the cystic duct after securing the proximal portion with vicryl $2 / 0$ is a safe and easy option for laparoscopic cholecystectomy. This method ultimately reduced the number to ports to 3 and the size of epigastric port from $10 \mathrm{~mm}$ to $5 \mathrm{~mm}$ and eliminating the need for titanium clips. The use of harmonic scalpel also reduces the risk of remote injury.

\section{Copyright@ 10 Oct, 2019.}

\section{REFERENCES}

1. Lillemoe KD, Lin JW, Talamini MA, Yeo CJ, Snyder DS, Parker SD. Laparoscopic cholecystectomy as a "true" outpatient procedure: Initial experience in 130 consecutive patients. J Gastrointest Surg. 1999 JanFeb. 3(1):44-9.

2. McSherry CK. Cholecystectomy: The gold standard. Am J Surg. 1989 Sep. 158(3):174-8.

3. Litwin DE, Cahan MA. Laparoscopic cholecystectomy. Surg Clin North Am. 2008 Dec. 88(6):1295-313.

4. Olsen DO. Laparoscopic cholecystectomy. Am J Surg. 1991; 161:339-344. doi: 10.1016/00029610(91)90592-2.

5. Litynski GS. Profiles in laparoscopy: Mouret, Dubois, and Perissat: The laparoscopic breakthrough in Europe (1987-1988) JSLS. 1999; 3:163-7.

6. Ghavidel A. Migration of clips after laparo-scopic cholecystectomy; A case report and literature review. Middle East J Dig Dis 2015; 71:45-49.

7. Ross O. Downes, Michael McFarlane, Charles Diggiss, James Iferenta. Single incision cholecystectomy using a clipless technique with LigaSure in a resource limited environment: The Bahamas experience. Int J Surg Case Rep. 2015; 11: 104-109

8. Osborne D, Boe B, Rosemurgy AS, Zervos EE. Twentymillimeter laparoscopic cholecystectomy: fewer ports results in less pain, shorter hospitalization, and faster recovery. Am Surg. 2005; 71:298-302.

9. Sarli L, Costi R, Sansebastiano G. Minilaparoscopic cholecystectomy vs laparoscopic cholecystectomy. Surg Endosc. 2001; 15:614-8. doi: $10.1007 / \mathrm{s} 004640000316$.

10. Denes B, de la Torre RA, Krummel TM, Oleson LSM. Evaluation of a vessel sealing system in a porcine model. (2003) In 21st World Congress of Endourology, Moderated poster session, Endourology/Laproscopy: Laboratory \& Teaching Montreal, Canada.

11. Nazih Salameh Amarin. Harmonic scalpel and clipless cholecystectomy. World Jounal of laparoscopic Surgery. May-Aug. 2008; 1:6-8.

12. Marshall Nicholas, T. Vu, D Patel. A clipless technique for laparoscopic cholecystectomy using the harmonic scalpel. ASGBI Oral presentation: Manchester on April 19th 2007 - Benign hepatobiliary section. 
13. Manoj Kumar, Chandra Shekhar Agrawal, Rakesh Kumar Gupta. Three-Port versus standard fourport laparoscopic cholecystectomy: A randomized controlled clinical trial in a community-based teaching Hospital in Eastern Nepal. JSLS. 2007 JulSep; 11(3): 358-362

14. Dhafir Al-Azawi, Nariman Houssein, Abu Bakir Rayis, Donal McMahon, Dermot $\mathrm{J}$ Hehir. Three-port versus four-port laparoscopic cholecystectomy in acute and chronic cholecystitis. BMC Surg. 2007; 7: 8.

15. Siddiqui NA, Azami R, Murtaza G, Nasim S. Postoperative port-site pain after gall bladder retrieval from epigastric vs. umbilical port in laparoscopic cholecystectomy: A randomized controlled trial. Int J Surg. 2012; 10(4):213-6. doi: 10.1016/j.ijsu.2012.03.008

16. Farr CM, Larson C, Gladen HE, Witherspoon L, Lesperance $R$, Moseley $D$. An iatrogenic gallstone with pancreatitis. J Clin Gastroenterol. 1989;11:596-7

17. Brutvan FM, Kampschroer BH, Parker HW. Vessel clip as a nidus for formation of common bile duct stone. Gastrointest Endosc. 1982; 28:222-3.

18. Margolis J. Recurrent choledocholithiasis due to hemostatic clip. Arch Surg. 1986; 121:1213.

19. Davis M, Hart B, Kleinman R. Obstructive jaundice from open vessel clip. Gastrointest Radiol. 1988; 13:259-60.
20. Janssen IMC, Swank DJ, Boonstra O, Knipscheer BC, Klinkenbijl JHG, van Goor H. Randomized clinical trial of ultrasonic versus electrocautery dissection of the gallbladder in laparoscopic cholecystectomy. $\mathrm{Br} \mathrm{J}$ Surg 2003; 90: 799-803.

21. Huang $X$, Feng $Y$, Huang $Z$. Complications of laparoscopic cholecystectomy in China: An analysis of 39,238 cases. Chin Med J (Engl) 1997; 110: 704-6.

22. Strasberg SM, Hertl M, Soper NJ. An analysis of the problem of biliary injury during laparoscopic cholecystectomy. J Am Coll Surg 1995; 180:101-25.

23. Foschi Diego, Cellerino Paola, Corsi Fabio, Previde Paolo, Allevi, Raffaele, Trabucchi Emilio. Closure of the cystic duct by ultrasonic energy: An electronmicroscopic and biomechanical study in man. Surgical Laparoscopy, Endoscopy \& Percutaneous Techniques. 2009; 19:34-38.

24. Gurusamy KS, Bong JJ, Fusai G, Davidson BR. Methods of cystic duct occlusion during laparoscopic cholecystectomy. Cochrane Database Syst Rev. 2010 Oct 6; (10):CD006807.

25. Rikki SINGAL, Muzzafar ZAMAN, Amit MITTAL, Samita SINGAL. The safety and efficacy of clipless versus conventional laparoscopic cholecystectomy - our Experience in an Indian Rural Center. Maedica (Buchar). 2018 Mar; 13(1): 44-50.

\begin{tabular}{|c|c|c|c|}
\hline \multicolumn{4}{|c|}{ AUTHORSHIP AND CONTRIBUTION DECLARATION } \\
\hline Sr. \# & Author(s) Full Name & Contribution to the paper & Author(s) Signature \\
\hline 1 & Ghulam Hassan & $\begin{array}{l}\text { Write up, Data collection, } \\
\text { analysis. }\end{array}$ & \\
\hline 2 & Saad Gulzar & Write up, Data collection. & \\
\hline 3 & Tariq lqbal & Data collection, analysis. & \\
\hline 4 & M. Imranul Haque & $\begin{array}{l}\text { Write up, Data collection, } \\
\text { analysis. }\end{array}$ & 8 \\
\hline
\end{tabular}

